\title{
Aplicação do Programa Cognitivo-Comportamental Superar para atendimento individual de meninas vítimas de violência sexual: estudos de caso
}

\author{
Aplicación del Programa Cognitivo-Comportamental Superar para el atendimiento \\ indiuidual de jóvenes víctimas de violencia sexual: estudios de caso \\ Application of Cognitive-Behavioral Program "Superar" to Individual \\ Treatment for Girls Uictims of Sexual Uiolence: Case Studies
}

\author{
Jaluza Aimèe Schneider*, Luísa Fernanda Habigzang* \\ *Pontifícia Universidade Católica do Rio Grande do Sul, Brasil.
}

Doi: http://dx.doi.org/10.12804/ap134.3.2016.08

\section{Resumo}

A violência sexual (VS) contra crianças e adolescentes é um grave problema de saúde pública que pode acarretar consequências negativas para o desenvolvimento cognitivo, comportamental e emocional. Intervenções psicológicas baseadas em evidências tornam-se indispensáveis para o manejo efetivo de sintomas e alterações decorrentes da VS. No Brasil, o Programa de Grupoterapia Cognitivo-Comportamental Superar possui evidências de efetividade, porém a prática clínica aponta a necessidade de intervenções no formato individual. O presente artigo visa a apresentar a aplicação deste programa em dois casos clínicos no formato individual. As meninas participantes (9 e 16 anos) foram vítimas de VS intrafamiliar. O processo terapêutico é descrito e os resultados indicaram a diminuição de sintomas de depressão e estresse. Além disso, antes da intervenção as meninas apresentavam critérios diagnósticos para transtorno do estresse pós-traumático que não foram preenchidos ao final desta. Verificou-se que o Programa Superar teve resultados positivos também no formato individual.

Palavras-chave: violência sexual; terapia cognitivo-comportamental; crianças; adolescentes.

\section{fbstract}

Sexual violence (SV) against children and adolescents is a serious public health problem that can have negative consequences for cognitive, behavioral and emotional development. Psychological evidence-based interven-

* Jaluza Aimèe Schneider, Programa de Pós-Graduação em Psicologia, Pontifícia Universidade Católica do Rio Grande do Sul, Brasil; ** Luísa Fernanda Habigzang, Programa de Pós-Graduação em Psicologia, Pontifícia Universidade Católica do Rio Grande do Sul, Brasil.

Correspondência a respeito deste artigo deve ser endereçada para Jaluza Aimèe Schneider, Programa de Pós-Graduação em Psicologia PUCRS, em Avenida Ipiranga, 6681, Partenon, CEP: 90619-900, Porto Alegre/RS/Brasil. Correio eletrônico: luisa.habigzang@pucrs.br

Cómo citar este artículo: Schneider, J. A. \& Habigzang, L. F. (2016). Aplicação do Programa Cognitivo-Comportamental Superar para atendimento individual de meninas vítimas de violência sexual: estudos de caso. Avances en Psicología Latinoamericana, 34(3), 543-556. doi: http://dx.doi.org/10.12804/apl34.3.2016.08 
tions become indispensable for the effective management of symptoms and changes resulting from VS. In Brazil, the Superar - Cognitive-behavioral group therapy Program has evidence of effectiveness, but clinical practice points to the need for interventions in individual format. This article aims to present the application of this program in two clinical cases in individual format. The participating girls (9 and 16) were victims of interfamilial VS. The therapeutic process is described and the results indicated a decrease in symptoms of depression and stress. Furthermore, before the intervention girls had diagnostic criteria for post-traumatic disorder that were not filled at the end of this. It was found that Superar Program also had positive results in the single format. Keywords: sexual violence; cognitive-behavioral therapy; children; adolescents.

\section{Resumen}

La violencia sexual (VS) contra niños y adolescentes es un grave problema de salud pública que puede acarrear consecuencias negativas para el desarrollo cognitivo, comportamental y emocional. Intervenciones psicológicas basadas en evidencias se volvieron indispensables para el manejo efectivo de síntomas y alteraciones decurrentes de la VS. En Brasil, el Programa de Grupoterapia Cognitivo-Comportamental Superar posee evidencias de efectividad, por lo cual la práctica clínica apunta a la necesidad de intervenciones en el formato individual. El presente artículo pretende presentar la aplicación de este programa en dos casos clínicos en el formato individual. Las jóvenes participantes ( 9 y 16 años) fueron víctimas de VS intrafamiliar. El proceso terapéutico es descrito y los resultados indicaron la disminución de síntomas de depresión y estrés. Además, antes de la intervención, las jóvenes presentaban criterios diagnósticos para el trastorno del estrés postraumático que no fueron tratados al final de ésta. Se confirmó que el Programa Superar tuvo resultados positivos también en el formato individual. Palabras clave: violencia sexual; terapia cognitivo-comportamental; niños; adolescentes.
A violência sexual é definida como envolvimento de crianças ou adolescentes em atividade sexual, sem total compreensão ou condições de consentimento para o ato (Organização Mundial da Saúde, 1999). É caracterizada por qualquer atividade entre uma criança ou adolescente e outro indivíduo de idade ou em estágio de desenvolvimento mais avançado, na qual ocorre a gratificação ou satisfação das necessidades sexuais deste. Tais atividades sexuais são impostas às crianças ou aos adolescentes pela violência física, ameaças ou indução de sua vontade. Dessa forma, a violência sexual variar desde atos nos quais não há o contato físico (voyeurismo, exibicionismo, produção de fotos), até diferentes tipos de ações com contato físico que incluam ou não penetração. Abrange, ainda, situações de exploração sexual, visando a lucro, tais como, a exploração sexual e a exposição à pornografia (Ministério da Saúde, 2002). A violência sexual trata-se de um problema de saúde pública capaz de causar consequências negativas para o desenvolvimento cognitivo, comportamental e emocional das vítimas (Habigzang \& Koller, 2011; Maniglio, 2009).

Dentre as principais consequências da violência sexual, destacam-se: percepção de diferença em relação aos pares, sentimentos de vergonha e medo, percepção de culpa, isolamento social, irritabilidade, alterações de sono e apetite, diminuição do rendimento escolar, entre outras (Cortés, Cantón, Justicia, \& Cortés, 2011; Maniglio, 2009). A experiência de vitimização sexual está relacionada ao desencadeamento e manutenção de sintomas psicopatológicos. Os transtornos de humor, transtornos de ansiedade, transtornos disruptivos, transtornos alimentares, enurese, encoprese e transtornos por uso de substâncias estão relacionados à vitimização sexual (Maniglio, 2009). Contudo, o transtorno do estresse pós-traumático (TEPT) é identificado como diagnóstico mais frequente em crianças e adolescentes vítimas à violência da espécie (Cohen, Deblinger, Mannarino, \& Steer, 2004; Passarela, Mendes, \& Mari, 2010). 
Tais alterações cognitivas, emocionais e comportamentais necessitam de criteriosa avaliação psicológica e práticas baseadas em evidências para intervenção psicoterapêutica. Os protocolos de intervenção para tratamento de vítimas de violência sexual devem estar de acordo com as diretrizes da World Health Organizatione da International Society for Preventionof Child Abuse and Neglect (WHO \& ISPCAN, 2006). As mencionadas diretrizes incluem: (a) as intervenções devem apresentar evidências de efetividade/eficácia verificadas pelo método de pesquisa; (b) as intervenções devem estabelecer objetivos terapêuticos; (c) as intervenções devem ser estruturadas (tempo limitado de sessões e atividades e técnicas definidas previamente); e (d) as intervenções devem abordar técnicas específicas e efetivas para manejo das consequências emocionais e comportamentais decorrentes da violência sexual e redução da intensidade e frequência dos sintomas identificados.

Os protocolos de terapia cognitivo-comportamental (TCC) para crianças e adolescentes vítimas de violência sexual estão de acordo com as referidas diretrizes (WHO \& ISPCAN, 2006) e apresentam resultados efetivos na redução de sintomas comuns em vítimas, tais como depressão e ansiedade (Cohen, Mannarino, \& Knudsen, 2005; Deblinger, Stauffer, \& Steer, 2001; Compton et al., 2004), TEPT (Cohen, Mannarino, \& Rogal, 2001; Cohen, Deblinger, Mannarino, \& Steer, 2004) e crenças e atribuições distorcidas em relação à violência (Celano, Hazzard, Campbell, \& Lang, 2002; Cohen \& Mannarino, 2002).

No Brasil, o modelo de grupoterapia cognitivo-comportamental Superar (Habigzang et al., 2009; Habigzang, Damásio, \& Koller, 2013) apresenta evidências de efetividade e seguem as diretrizes (WHO\& ISPCAN, 2006). O modelo referido constitui-se por 16 sessões semi-estruturadas, divididas em três etapas: (1) psicoeducação e reestruturação cognitiva; (2) treino de inoculação do estresse; e (3) prevenção à recaída, de acordo com os objetivos e técnicas empregadas. Os resultados do ensaio clínico intragrupos com medidas repetidas, realizado para avaliar a efetividade do modelo, apontaram para a redução de sintomas de depressão, ansiedade, estresse e TEPT. Tais resultados foram mantidos após seis e 12 meses do término da intervenção (Habigzang et al., 2009; Habigzang et al., 2013).

Ainda no contexto brasileiro, foi identificado um estudo de caso com uma menina de 13 anos vítima de violência sexual, utilizando a terapia cognitivo-comportamental (Lucânia, Valério, Barison, \& Miyazaki, 2009). A intervenção foi composta por 45 sessões. A avaliação do processo de psicoterapia e do relato da menina indicaram melhora nos sintomas de TEPT, depressão e em dificuldades de comportamento.

Considerando o número reduzido de sessões e as evidências de efetividade do programa Superar, o presente estudo teve como objetivos adaptar para o formato individual e apresentar a utilização deste programa para dois casos de meninas vítimas de violência sexual. Tal adaptação se mostrou necessária, uma vez que nem todos profissionais ou instituições contam com espaço físico e/ou demanda suficiente para formação de grupos terapêuticos, conforme sugere o programa original do Superar.

\section{Método}

\section{Delineamento}

Trata-se de estudos de casos clínicos, com avaliação antes (pré-teste) e depois (pós-teste) da intervenção.

\section{Participantes}

O estudo foi realizado com dois casos clínicos. A participante I é uma menina de nove anos, estudante do segundo ano do ensino fundamental, que residia com o avô materno. Esta foi encaminhada pelo Juizado da Infância e Juventude para acompanhamento psicológico devido à situação de 
violência sexual perpetrada pelo pai. Tal situação ocorreu após a morte da sua mãe. A menina não teve convivência com o pai até o falecimento da sua mãe, quando passou a frequentar a casa dele nos finais de semana. A violência sexual foi revelada para família materna após o avô perceber alguns comportamentos sexualizados na criança, quando esta tinha oito anos. A violência teve início quando a menina tinha seis anos de idade. Após revelação, $\mathrm{o}$ avô adotou como medida protetiva o afastamento do pai. Contudo, o avô não notificou o caso às autoridades. O Juizado somente tomou conhecimento da situação de violência em uma audiência, na qual o pai solicitava a guarda da filha.

A participante II é uma adolescente de 16 anos, estudante do sétimo ano do ensino fundamental com histórico de repetência escolar (três vezes). A menina apresentava comportamentos agressivos na escola e dificuldades de aprendizagem, segundo os professores. A mesma residia com seus pais e dois irmãos. O encaminhamento para acompanhamento psicológico foi realizado pelo Conselho Tutelar (CT) após a adolescente revelar situações de violência sexual perpetradas por seu avô materno. Tal violência ocorreu entre os 6 e 8 anos de idade e foi interrompida pelo afastamento do avô quando a família tomou conhecimento de interações abusivas deste com a irmã mais velha da participante. A adolescente somente revelou também ter sido vítima de violência aos 16 anos quando foi encaminhada ao CT devido a comportamentos agressivos na escola.

\section{Instrumentos}

Os instrumentos psicológicos utilizados neste estudo foram:

\section{Entrevista semi-estruturada}

Tem como objetivos estabelecer vínculo terapêutico e obter relato sobre a violência sexual, dinâmica, padrão de revelação e medidas de proteção adotadas (baseada no protocolo The Metropolitan Toronto Special Committeeon Child Abuse, 1995, traduzida para o português por Kristensen, 1996).

\section{Escala de Estresse Infantil (ESI)}

É composta por 35 itens relacionados às reações físicas, psicológicas, psicológicas com componente depressivo e psicofisiológica do estresse. A resposta ao item é feita por meio de uma escala de cinco pontos, na qual a criança/adolescente pinta um círculo dividido em quatro partes, conforme a frequência com que experimentam os sintomas referidos pelos itens (Lipp \& Lucarelli, 1998).

\section{Inventário de Depressão Infantil (CDI)}

Elaborado por Kovacs (1992), foi adaptado do Beck Depression Inventory para adultos. O objetivo do CDI é identificar a presença e a severidade de sintomas de depressão. É composto por 27 itens, cada um com três opções de resposta.

\section{Entrevista estruturada com base no DSM IVI SCID para avaliação de transtorno do estresse pós-traumático}

Tem como objetivo avaliar os sintomas que compõem o TEPT, com base nos critérios diagnósticos estabelecidos pelo Manual Diagnóstico e Estatístico dos Transtornos Mentais IV (DSM-IV). A tradução para o português desta entrevista foi desenvolvida por Del Bem et al. (2001) e adaptada para crianças e adolescentes por Habigzang (2006).

\section{Procedimentos}

As participantes deste estudo estão incluídas em uma pesquisa mais ampla aprovada pelo comitê de ética da Universidade Federal do Rio Grande do Sul, protocolo 2005526. A pesquisa segue as orientações da Resolução no 466/2012 do Conselho Nacional de Saúde. Os(as) cuidadores responsáveis 
pelas participantes foram consultados sobre a participação no estudo e assinaram o termo de consentimento livre esclarecido (TCLE). Da mesma forma, também foram as meninas participantes consultadas sobre sua participação no estudo, aceitando e assinando o TCLE. Esta intervenção foi realizada em um programa de extensão da Universidade situado na Região Metropolitana de Porto Alegre/ RS. A avaliação psicológica e os atendimentos realizados foram conduzidos por acadêmicos de psicologia em estágio com supervisão semanal de psicólogo com ampla experiência clínica em casos de violência sexual.

A avaliação psicológica, composta por três sessões com frequência semanal e duração de uma hora cada, foi realizada antes do início da intervenção terapêutica. No primeiro encontro, se realizou à entrevista semi-estruturada, com o objetivo de conhecer a história da violência sexual, assim como de fatores de risco e proteção envolvidos no caso. O segundo e terceiro encontros foram designados para a aplicação dos instrumentos que avaliaram sintomas de TEPT, depressão e estresse. Após a avaliação psicológica, foi realizada entrevista de devolução para os(as) cuidadores e para as participantes, com objetivos de compartilhar os resultados e indicar processo psicoterapêutico. O processo psicoterapêutico foi composto por 16 sessões individuais com estrutura adaptada do modelo Superar para grupos (ver tabela 1). Dando seguimento, foram reaplicados os instrumentos da avaliação psicológica que avaliaram TEPT, depressão e estresse.

As adaptações referentes ao modelo de intervenção grupal realizadas foram: (1) tempo de duração para 50 minutos no formato individual e (2) atividades previstas para grupo foram modificadas para execução individual. O número de encontros e os objetivos de cada sessão foram mantidos. As alterações de atividades estão descritas na tabela

Tabela 1

Alterações para adaptação do formato grupal para formato individual de intervenção

\begin{tabular}{|c|c|c|}
\hline Sessão & Formato grupal & Formato individual \\
\hline 1 & $\begin{array}{l}\text { Dinâmica de grupo para apresentação das participantes; dinâmica de } \\
\text { grupo para desenvolver confiança; estabelecimento de contrato terapêu- } \\
\text { tico (horário, frequência, duração); discussão sobre identidade do grupo; } \\
\text { mapeamento a partir da construção de um cartaz sobre as expectativas do } \\
\text { grupo; discussão e estabelecimento dos objetivos do grupo. }\end{array}$ & $\begin{array}{l}\text { Estabelecimento do contrato terapêu- } \\
\text { tico (horário, frequência e duração); } \\
\text { mapeamento das expectativas da } \\
\text { paciente; estabelecimento de objetivos } \\
\text { terapêuticos. }\end{array}$ \\
\hline 2 & $\begin{array}{l}\text { Apresentação e discussão do documentário "Canto de Cicatriz"; Relato } \\
\text { de experiência de violência sexual de cada participante; Restruturação de } \\
\text { crenças distorcidas sobre o violência; Abordagem do impacto afetivo da } \\
\text { revelação no grupo. }\end{array}$ & Manteve-se igual. \\
\hline 3 & $\begin{array}{l}\text { Abordagem das reações da família e demais pessoas significativas após a } \\
\text { revelação da violência sexual; construção do mapeamento das possíveis } \\
\text { mudanças na configuração famíliar (dispositivo: livro "minha família } \\
\text { antes e depois da revelação"); reestruturação cognitiva das crenças rela- } \\
\text { cionadas a culpa e vergonha (construção de cartões de enfrentamento). }\end{array}$ & Manteve-se igual. \\
\hline 4 & $\begin{array}{l}\text { Psicoeducação quanto ao modelo cognitivo-comportamental; abordagem } \\
\text { dos estados emocionais (dispositivo: jogo das emoções); abordagem } \\
\text { terapêutica dos sentimentos com relação ao agressor (dispositivo: cons- } \\
\text { trução do agressor com massa de modelar e role-play entre paciente e } \\
\text { boneco); automonitoramento (registro de situações problema e sentimen- } \\
\text { tos identificados). }\end{array}$ & Manteve-se igual. \\
\hline
\end{tabular}

Continúa 


\begin{tabular}{clc}
\hline Sessão & \multicolumn{1}{c}{ Formato grupal } & Formato individual \\
\hline \multicolumn{3}{c}{$\begin{array}{l}\text { Discussão dos registros de automonitoramento; psicoeducação quanto } \\
\text { ao modelo cognitivo-comportamental, abordagem dos pensamentos e } \\
\text { reações fisiológicas e suas relações com as emoções; identificação de } \\
\text { pensamentos com relação a violência sexual e reestruturação cognitiva } \\
\text { de pensamentos disfuncionais (tríade cognitiva); aprendizagem de técni- } \\
\text { cas de relaxamento muscular e de respiração controlada para controle de } \\
\text { ansiedade; automonitoramento (registros de situações-problema, pensa- } \\
\text { mento, reações fisiológicas e sentimentos relacionados). }\end{array}$} \\
\hline
\end{tabular}

Discussão dos registros do automonitoramento; psicoeducação quanto ao modelo cognitivo-comportamental, abordagem dos comportamentos e sua relação com pensamentos, sentimentos e reações fisiológicas; mapeamento escrito das principais mudanças de comportamentos

6 pensamentos e emoções decorrentes da violência sexual; psicoeducação quanto ao problema - estabelecimento de relações entre violência/trau-

Manteve-se igual. ma com mudanças identificadas no mapeamento; construção de história em quadrinhos, a partir de situação registrada, com identificação de emoções, pensamentos, comportamentos e reações fisiológicas para integrar o modelo cognitivo-comportamental.

Treino de inoculação do estresse (TIE) - Apresentação, de forma gra-

7 dual, das situações de violência experienciadas, por meio de relato oral e escrito; reestruturação cognitiva das memórias traumáticas (treino de Manteve-se igual. autoinstrução); relaxamento.

Relato mais detalhado da violência sexual; mapeamento da frequência e

8 intensidade das lembranças e dos eventos desencadeadores destas; treino Manteve-se igual. de relaxamento.

\begin{tabular}{cll}
\hline 9 & $\begin{array}{l}\text { Relato mais detalhado da violência sexual; técnica de substituição de } \\
\text { imagens positivas e negativas (gavetas da memória). }\end{array}$ & Manteve-se igual. \\
10 & $\begin{array}{l}\text { Relato do pior momento da violência sexual; construção do "botão de } \\
\text { emergência" com estratégias cognitivas e comportamentais para lidar } \\
\text { com lembranças intrusivas da violência; relaxamento. }\end{array}$ & Manteve-se igual. \\
\hline 11 & $\begin{array}{l}\text { Oficina de sexualidade: Jogo em grupo com perguntas das participantes } \\
\text { sobre mudanças no corpo, relacionamentos amorosos e sexuais e estraté- } \\
\text { gias de autocuidado. }\end{array}$ & $\begin{array}{l}\text { Dúvidas sobre sexualidade abordadas } \\
\text { a partir de conversa entre terapeuta e } \\
\text { paciente. }\end{array}$ \\
\hline 12 & $\begin{array}{l}\text { Oficina de expressão corporal: Realização de jogos e dinâmicas de grupo } \\
\text { que envolva relação com o corpo. }\end{array}$ & $\begin{array}{l}\text { Abordagem da expressão corporal por } \\
\text { meio do espelho, brincadeiras e/ou } \\
\text { conversas sobre toques abusivos e não } \\
\text { abusivos. }\end{array}$ \\
\hline 13 & $\begin{array}{l}\text { Oficina sobre o Estatuto da Criança e do Adolescente: Apresentação e } \\
\text { discussão do vídeo sobre o ECA; construção de painel sobre o ECA; } \\
\text { esclarecimento de dúvidas sobre audiência. }\end{array}$ & Manteve-se igual. \\
\hline 14 & $\begin{array}{l}\text { Treino de habilidades sociais focadas em medidas protetivas; escolha de } \\
\text { um adulto-referência para solicitar ajuda em situação de risco. }\end{array}$ & $\begin{array}{l}\text { Manteve-se igual. } \\
\text { Retomada das estratégias cognitivas e comportamentais aprendidas na } \\
\text { turação de possíveis crenças destorcidas (Máquina do Tempo). }\end{array}$ \\
\hline
\end{tabular}


1.Os resultados foram analisados considerando o processo, por meio da análise do conteúdo dos registros dos atendimentos, e o impacto, por meio da comparação dos resultados dos instrumentos psicológicos aplicados antes e após a intervenção.

\section{Resultados}

Os resultados deste estudo serão apresentados considerando o processo e o impacto do tratamento. No processo serão descritas as intervenções realizadas nas três etapas do modelo Superar, conforme apresentado na tabela 1. A avaliação de impacto apresenta os resultados dos instrumentos psicológicos que avaliaram sintomas de depressão, estresse e TEPT aplicados antes e depois do tratamento.

\section{Processo terapêutico}

\section{Etapa 1: psicoeducação e reestruturação cognitiva}

A primeira etapa, realizada em seis sessões, contemplou o contrato terapêutico, psicoeducação quanto à violência sexual e ao modelo da terapia cognitivo-comportamental, identificando e reestruturando os aspectos cognitivos, emocionais e comportamentais que se apresentam disfuncionais por consequência da violência sexual (Habigzang et al., 2009). Na primeira sessão, a terapeuta iniciou com um rapport, apresentando-se para as meninas e solicitando que também se apresentassem. Os objetivos foram estabelecer vínculo, combinações sobre os atendimentos e verificar expectativas sobre o processo terapêutico. Para a participante I foram disponibilizados brinquedos a fim de facilitar o vínculo. Já com a participante II, efetuou-se conversa inicial.

$\mathrm{Na}$ segunda sessão foi realizada a psicoeducação sobre violência sexual e o documentário "Canto de Cicatriz" foi apresentado e discutido. As duas meninas salientaram os relatos que aparecem no documentário de mulheres que sofreram violência sexual na infância e que conseguiram encontrar formas para superar o trauma e elaborar um projeto de vida saudável. O mito sobre a responsabilização da vítima foi discutido pela participante I, tendo a mesma manifestado sentir-se culpada pela violência. A participante II expressou sentimentos de raiva e nojo durante seu relato e disse que pensava ser a única menina que havia passado por situações abusivas. Por fim, a terapeuta estimulou as meninas a relatarem sua experiência de violência. As participantes narraram situações de violência com alguns detalhes. Ao final da sessão, foi avaliado o impacto emocional oriundo das declarações.

A terceira sessão abordou as reações da família frente à revelação de violência, sendo elaborado pelas meninas um livro de história apontando como eram suas famílias antes e depois da revelação. As duas meninas informaram que houve o afastamento do agressor e a participante II ressaltou o incômodo estar gerado no ambiente familiar após a revelação. Algumas emoções negativas, como vergonha e culpa, apareceram nesta sessão e indicaram pensamentos distorcidos relacionados à experiência abusiva. A reestruturação cognitiva de tais pensamentos baseou-se na elaboração de evidências que apoiavam e que refutavam o pensamento que responsabilizava as meninas pela violência. Devido à idade da participante $\mathrm{I}$, foi utilizado recurso lúdico para aplicação da técnica. O uso de personagem de desenho animado serviu como um facilitador na checagem de evidências em relação à culpa. A menina falou sobre os Pokemóns. Comparou seu pai ao Pokemón mais evoluído porque tinha habilidades melhores desenvolvidas (força, inteligência e agilidade), fatores que impossibilitavam que ela vencesse a "batalha" da violência. Segundo a menina, por ser "pequena", ainda não tinha habilidades suficientes para se defender. Já a participante II engajou-se em um questionamento socrático e identificou circunstâncias que refutavam a crença de que tinha responsabilidade pela violência. No final da sessão, as meninas construíram um cartão de enfrentamento, contendo afirmações reforçadoras 
da responsabilidade do agressor pela violência. A participante I assim redigiu:"o adulto é que deveria saber das coisas certas, não eu sendo criança; ele me segurava e tapava minha boca, porque era mais forte e eu não conseguia sair; eu não sou culpada ele que não deveria fazer isso".

A quarta sessão iniciou com o "jogo das emoções", consistente em identificar emoções que poderiam ser experienciadas em diferentes situações apresentadas pela terapeuta. Este auxiliou a participante I a superar sua dificuldade em identificar e nomear suas emoções, tal dificuldade não foi verificada na participante II. Na sequência, as meninas construíram o agressor em massa de modelar, com objetivo de externalizar emoções e pensamentos sobre o mesmo por meio de um role-play. Para a participante II, o role-play se mostrou a técnica de maior relevância da sessão. A adolescente conseguiu elucidar seus sentimentos em relação ao agressor e, após manifestar sua raiva e tristeza, revelou sentir-se aliviada. Uma das frases verbalizadas pela jovem foi: "Tu (agressor) nunca foi meu avô de verdade, eu te odeio, o que tu fez não se faz para ninguém, tu só pode ser doente".

$\mathrm{Na}$ quinta sessão, a psicoeducação quanto ao modelo abordou os pensamentos. Foi explicado que pensamentos são ideias, lembranças e imagens que passam pela nossa cabeça. As meninas realizaram uma atividade para mapear a tríade cognitiva (visão de si, dos outros e do futuro). Sobre a tríade cognitiva da participante II, destaca-se: (1) Visão de si: "Eu penso porque eu sou assim e porque tudo isso aconteceu comigo e penso se eu poderia ser melhor do que sou agora (...)"; (2) Visão dos outros: "Porque elas estão comigo? Se elas gostam mesmo de mim, se elas querem me ajudar ou estão comigo por interesse."; (3) Visão do futuro: “Eu penso que meu futuro vai ser melhor que o meu agora e que meu passado. Que não vou mais sofrer e nem ter mais nenhum problema com ninguém". Depois de analisada a abordagem dos pensamentos, as meninas aprenderam a identificar mudanças que ocorrem no corpo quando sentem emoções intensas. Técnicas de relaxamento muscular e respiração controlada foram conduzidas para controle de alterações fisiológicas. A participante I teve dificuldade de concentração para realizar o exercício de relaxamento referente à respiração controlada. Porém, a menina avaliou que o relaxamento muscular foi bom, sendo efetivo no seu propósito. Já para a adolescente, a respiração controlada resultou em maior relaxamento, possibilitando o alcance dos objetivos de técnica.

Para finalizar a psicoeducação quanto ao modelo cognitivo-comportamental, na sexta sessão foi abordado o que é comportamento e sua relação com emoções, pensamentos e reações fisiológicas. A partir de situações registradas no automonitoramento, as meninas criaram histórias em quadrinhos identificando os elementos do modelo cognitivo. A participante II reproduziu uma situação em que sua melhor amiga estava namorando e, com isso, a deixava sozinha durante o recreio na escola. Sua emoção foi de raiva, com suor nas mãos, e seu pensamento indicou não aceitar a troca de uma amizade por um garoto, razão pela qual o comportamento adotado pela adolescente foi de afastamento da amiga. Após finalizar essa atividade, foi realizada à construção de um mapa contendo as alterações cognitivas, comportamentais e emocionais em decorrência da violência. A adolescente identificou as seguintes alterações: irritabilidade, abandono de hábitos lúdicos, comportamentos agressivos e desconfiança. Tais alterações podem ser averiguadas no seguinte relato: "Eu brincava muito antes de ter começado o abuso. Depois que começou eu parei de brincar e comecei a brigar muito com todo mundo, comecei a fazer coisas erradas, xingava todo mundo por nada, não acreditava nas pessoas que estavam do meu lado".

\section{Etapa 2: treino de inoculação do estresse}

A segunda etapa da intervenção consiste no treino de inoculação do estresse (TIE), compreendendo quatro sessões. O TIE é realizado na perspectiva 
de controle das emoções pertinentes às lembranças do trauma e reestruturação da memória traumática. Para tanto, são realizadas técnicas que viabilizem respostas adaptativas para os pensamentos que surgem junto com a lembrança e aumento das habilidades de enfrentamento (Friedman, 2009). São construídas narrativas sobre as interações sexualmente abusivas, buscando organizar e ressignificar a memória traumática. Técnicas de relaxamento, autoinstrução e substituição de imagens mentais são associadas à construção de narrativas objetivando estabelecer autocontrole. No final dessa etapa, um cartão de enfrentamento chamado "Botão de Emergência" é criado com estratégias cognitivas e comportamentais para lidar com lembranças traumáticas. A paciente I apresentou dificuldade para escrever sobre a violência ocorrida, evidenciando, em vários momentos, o sentimento de vergonha sobre o assunto. Como nas demais sessões, a participante II apresentou facilidade na escrita, descrevendo com detalhes as situações de violência sexual vivenciadas.

Eu tava indo para escola uma vez e ele estava me esperando parado na estrada e eu tentei passar reto, mas ele me parou e me levou para um canto da rua onde ninguém passava e não via nada. Daí ele abaixou sua calça e mandou eu passar a mão e eu disse que não queria. Daí ele pegou minha mão e ele mesmo passou, dai eu comecei a chorar e ele não parou. (...) Ele passava minha mão e eu via que ele tava gostando eu não estava gostando, nem um pouco, estava odiando, sentindo nojo. Eu pedia para parar e ele não parava e aquilo me dava mais ódio dele ainda (Relato da participante II).

A técnica da autoinstrução foi melhor compreendida pela participante II, sendo que a participante I necessitou escrever os diálogos internos em um cartão de enfrentamento para facilitar o entendimento devido à sua idade. Diferença significativa entre as duas pacientes também foi verificada quanto à realização da técnica de substituição de imagens. A técnica consiste na construção de imagens mentais de um evento positivo experienciado e de um evento relacionado à violência sexual. $\mathrm{Na}$ sequência, a substituição das imagens mentais é conduzida pela terapeuta. A dificuldade no caso da participante I foi relativa à concentração e à realização da substituição de imagens de forma eficaz, uma vez que a técnica exige pensamento abstrato e seu estágio desenvolvimental era operatório-concreto. Foram realizados desenhos dos eventos positivo e negativo e as gavetas de um móvel da sala de atendimento foram utilizadas de forma a reproduzir o funcionamento da memória, facilitando o processo de substituição de imagens. Tal adaptação viabilizou o emprego da técnica.

$\mathrm{Na}$ última sessão da segunda etapa foi desenvolvido o "Botão de Emergência", momento em que foi oportunizado às pacientes pensaram em alternativas próprias, além de retomar as estratégias aprendidas em terapia. A participante I relatou que o cartão de enfrentamento sobre culpa e autoinstrução foi a estratégia que mais a ajudou a lidar com as lembranças intrusivas, deixando esse dispositivo de forma destacada no seu "Botão de Emergência”. Pela participante II foi apontada a técnica de substituição de imagens como a que mais facilitou o controle de suas lembranças e de suas reações emocionais negativas.

\section{Etapa 3: prevenção à recaída}

A terceira etapa da intervenção é a prevenção à recaída. $\mathrm{O}$ objetivo é aprender e ampliar habilidades de autoproteção, assim como retomar as estratégias aprendidas durante a intervenção para lidar com lembranças intrusivas. A décima primeira sessão tem como finalidade esclarecer dúvidas existentes sobre sexualidade. No caso da participante I, não existiam perguntas sobre este tema, o que pode ser justificado pela idade da mesma. Pela a ausência de questões a respeito, a terapeuta realizou com a menina a apresentação de algumas figuras, femininas e masculinas, efetuando abordagem sobre as 
diferenças entre sexos. Para a adolescente, foi de relevante importância a sessão em que abordados assuntos sobre sexualidade, pensando que a participante II já mantinha relações sexuais com seu namorado. A adolescente expôs diversas dúvidas relacionadas à gravidez, métodos anticonceptivos, doenças sexualmente transmissíveis, entre outras, sendo os questionamentos discutidos com enfoque psicoeducativo.

Na sessão seguinte, oficina de expressão corporal, foi possível realizar algumas brincadeiras com a participante I, como "morto-vivo" e "estátua", permitindo maior descontração, e, para lidar com o movimento de seu corpo. Em seguida, foi solicitado à menina que ficasse em frente ao espelho e tocasse em algumas partes de seu corpo, possibilitando análise sobre toques abusivos e não abusivos. Para a adolescente foi dispensada a brincadeira, não sendo adequada para sua idade e poderia se tornar inconveniente diante da demanda apresentada pela mesma. Desse modo, mostrou-se mais importante a abordagem acerca das diferenças entre toques abusivos e não abusivos, especialmente tendo em conta sua dificuldade para lidar com contatos físicos.

A décima terceira sessão teve como objetivo a apresentação e debate sobre o Estatuto da Criança e do Adolescente (ECA). Foi apresentado o documentário "Se Liga no Estatuto", o qual destaca temas sobre direitos fundamentais e rede de proteção existente. Encerrado o vídeo, a participante I confeccionou um cartaz com figuras e palavras que representavam os direitos definidos no ECA. Com a participante II, a abordagem se deu mediante conversa, na qual foram esclarecidas dúvidas e opiniões sobre seus direitos. As explicações em relação ao que são os Conselhos Tutelares foram importantes em ambos os casos, uma vez que as meninas demonstraram desconhecimento do que realmente se tratava. As participantes também não tinham conhecimento prévio sobre o próprio ECA, o que evidencia a necessidade da respectiva sessão a fim de fornecer elucidações sobre direitos previstos na legislação especial.

$\mathrm{Na}$ décima quarta sessão foi realizado um treino de habilidades sociais usadas como medida protetiva para as vítimas. Inicialmente, houve a discussão sobre o que são situações de risco e identificadas possíveis experiências de risco. As situações de risco podem variar com a idade e o contexto de cada paciente. No caso da participante I, os riscos identificados foram sobre ficar sozinha em casa e brincar longe de responsáveis. A menina declarou que seu avô combinou algumas estratégias de proteção com ela: não aceitar presentes de estranhos e do pai (agressor), esperar dentro da escola até que alguém da sua família a busque, saber pedir ajuda quando precisar, não ficar sozinha sem adultos conhecido, entre outros. Já para a participante II, os riscos estavam em beber em uma festa, "ficar" com algum menino desconhecido, não ficar em um lugar sozinha com algum garoto, questões que estão mais associadas à fase da adolescência. Após identificação das situações de potencial risco foram discutidas, elaboradas e ensaiadas por meio de role play as estratégias de proteção.

A décima quinta sessão tem como objetivo retomar estratégias aprendidas durante o processo terapêutico para lidar com lembranças da violência sexual. Além disso, teve como foco a construção de um projeto de vida por meio da técnica da "Máquina do Tempo". A participante II apresentou perspectivas adequadas para seu futuro, avaliando se suas pretensões eram passíveis de serem conquistadas ou não. No caso da participante I, a menina teve dificuldades para se imaginar em longo prazo, sendo a vida adulta muito distante de si.

A última sessão, a décima sexta, foi reservada para uma autoavaliação das pacientes sobre o processo terapêutico. Tanto a participante I quanto a participante II avaliaram a intervenção como benéfica, evidenciando aprendizagem de manejos de enfrentamento e diminuição de seu sofrimento. O relato escrito da participante I sobre a intervenção 
deixou claro quais foram as intervenções que tiveram maior êxito para si, como os cartões de enfrentamento, aprender sobre o ECA e o "Botão de Emergência”. A participante II conseguiu expressar de forma clara o quanto a intervenção foi positiva em sua percepção.

No início eu estava péssima, muito mal, não queria nada com nada e fazia tudo errado mesmo sabendo das consequências. Tudo isso por causa de um acontecimento que ocorreu quando eu tinha sete anos, isso me marcou muito, foi a pior coisa que me aconteceu. Por isso me deixou rebelde, brigava com todos, até mesmo se não tivesse motivo, estava sempre emburrada, estressada, chorando, lembrando de tudo aquilo que o abuso do pai da minha mãe comigo, neta dele, eu achava isso um absurdo. Com o tempo eu consegui superar, aos poucos, mas consegui. Fui usando botões de emergência que me ajudou bastante, fui abrindo e fechando janelas. Esse foi o mais difícil. Tinha medo de não conseguir fechar uma janela ruim, mas eu consegui porque apesar de coisas ruins terem acontecido comigo, coisas boas também aconteceram e foi com as pessoas mais importantes da minha vida, minha família. E esse é o final, não o final verdadeiro, mas sim o final de todo aquele sofrimento que eu tinha porque consegui superar tudo aquilo com uma ajuda e com a minha força de vontade. Tudo foi ótimo pra mim, pensei que não ia ajudar em nada vindo a psicóloga, mas ajudou, ela sim sabe como mudar uma pessoa.

\section{Impacto da intervenção}

Instrumentos para avaliação de sintomas de depressão, estresse e TEPT foram aplicados antes (pré-teste) e após (pós-teste) a intervenção. Verifica-se que a participante I apresentou redução nos sintomas de depressão, nas reações psicofisiológicas do estresse e, ao final da intervenção, não fechou critérios diagnósticos para TEPT. A participante II apresentava, antes da intervenção, pontuação no CDI que indicava depressão (pontuação > 19), indicadores de estresse e diagnóstico de TEPT. Já com o término do processo psicoterapêutico, a adolescente reduziu os sintomas de depressão, estresse e não fechou critérios diagnósticos para TEPT. Os resultados estão apresentados na tabela 2 .

Tabela 2

Resultados pré e pós-teste nos instrumentos que avaliaram depressão, estresse e TEPT

\begin{tabular}{|c|c|c|c|c|}
\hline \multirow{2}{*}{ Instrumento } & \multicolumn{2}{|c|}{ Participante I } & \multicolumn{2}{|c|}{ Participante II } \\
\hline & Pré-teste & Pós-teste & Pré-teste & Pós-teste \\
\hline Depressão - CDI & 12 & 03 & 22 & 04 \\
\hline \multicolumn{5}{|l|}{ Estresse - ESI } \\
\hline Reações físicas & 09 & 06 & 19 & 08 \\
\hline Reações psicológicas & 12 & 12 & 16 & 06 \\
\hline Reações psicológicas c/ comp. depressivo & 01 & 00 & 24 & 01 \\
\hline Reações psicofisiológicas & 10 & 02 & 21 & 10 \\
\hline Total & 32 & 20 & 80 & 25 \\
\hline \multicolumn{5}{|l|}{ TEPT - Entrevista estruturada } \\
\hline Presença de diagnóstico & Sim & Não & Sim & Não \\
\hline
\end{tabular}




\section{Discussão}

A intervenção terapêutica em situações de violência sexual é imprescindível, devido às repercussões negativas em nível cognitivo, comportamental e emocional. Crianças e adolescentes vítimas de violência sexual possuem alto risco para o desenvolvimento de psicopatologias em curto ou longo prazo, como transtorno do estresse pós-traumático, depressão, transtorno por uso de substâncias, transtornos de personalidade, suicídio, comportamentos sexuais desadaptativos, agressividade, entre outros (Macdonald et al., 2012; Whitaker, Le, Hanson, Baker, \& Mcmahon, 2008). Práticas baseadas em evidências devem ser adotadas para o tratamento de vítimas de violência sexual, visando à redução de sintomas e reestruturação da memória traumática. O modelo grupal do Programa Superar apresenta boas evidências de efetividade (Habigzang et al., 2013) e foi desenvolvido considerando aspectos contextuais do Brasil. Dessa forma, o presente artigo buscou adaptar e avaliar este programa de psicoterapia cognitivo-comportamental no atendimento individual de meninas vítimas de violência sexual, uma vez que nem sempre a demanda de casos é suficiente para a formação de grupos e os locais podem não apresentar estrutura física adequada para atendimentos grupais.

Poucas sessões sofreram alterações nas atividades previstas (ver tabela 1). Adequações nas técnicas foram realizadas de acordo com a etapa desenvolvimental das participantes (criança e adolescente). Os resultados indicaram a redução dos sintomas de TEPT, depressão e estresse nos dois casos, assim como verificado no estudo original em formato grupal (Habigzang et al., 2013). Também foi observada, durante o processo terapêutico, a redução de comportamentos desadaptativos decorrentes da violência sexual, assim como a reestruturação de crenças distorcidas sobre a mesma. Na intervenção individual foi possível identificar quais técnicas foram mais úteis para cada paciente.
A presença de critérios para diagnóstico de TEPT no início da intervenção e a ausência ao final sugere que as técnicas realizadas focadas no trauma foram efetivas em ambos os casos, o que está apoiado na literatura (Cohen et al., 2004; Habigzang et al., 2013). A partir dos resultados pode-se evidenciar que o TIE, proposto na segunda etapa da intervenção, cumpriu com o objetivo de reestruturação da memória traumática. A diminuição da pontuação na escala CDI, que avaliou depressão infantil, pode estar relacionada com a reestruturação de pensamentos disfuncionais geradores de sentimentos de culpa, vergonha, raiva e desesperança. Explorar tais emoções e crenças desadaptativas na intervenção, assim como psicoeducar sobre o que é violência sexual, sugere ter impacto positivo nos sintomas de depressão. Também foi identificada a redução nos escores da escala ESI que avaliou estresse infantil. A redução de tais sintomas pode ser proveniente do próprio contexto terapêutico, que possibilitou um espaço de escuta com o reconhecimento e aceitação dos sentimentos das vítimas de forma empática. Tal contexto vivenciado em uma relação terapêutica pode contribuir para alterar crenças disfuncionais comuns em vítimas de abuso sexual e que gerem estresse, tal como a crença de que relações interpessoais representam risco e abuso. Os processos terapêuticos das meninas apontaram bom vínculo com a terapeuta e boa adesão à técnica cognitivo-comportamental.

As principais limitações deste estudo estão relacionadas à: (1) ausência de casos-controle para verificar se as mudanças evidenciadas se devem a intervenção e (2) ausência de followup para acompanhar a manutenção ou não dos efeitos da intervenção. Além disso, a gravação das sessões permitiria uma avaliação de processo mais aprofundada por meio de instrumentos que permitissem avaliar elementos como a aliança terapêutica, por exemplo. A avaliação do processo foi realizada por meio da análise dos registros da terapeuta que podem apresentar importante viés subjetivo. 
Os estudos de caso representam importante estratégia para pesquisa em psicoterapia, constituindo uma etapa inicial no processo de evidências de efetividade de intervenções. Apesar da aplicação do Programa Superar em dois casos clínicos, que inviabiliza a generalização dos resultados, verificou-se a adequação da intervenção ao formato individual. Dessa forma, tal tratamento pode trazer benefícios a crianças e adolescentes atendidos tanto no formato individual quanto no formato grupal. O formato individual pode ser utilizado por profissionais que não possuem casos homogêneos para constituição de grupos ou que não tenham recursos físicos adequados em seus locais de trabalho. É importante salientar que a intervenção psicoterapêutica deve ser uma das ações que compõem o enfrentamento da violência sexual. O trabalho da psicologia no contexto clínico é parte do trabalho que deve ser desenvolvido por uma rede complexa de instituições que visam à proteção, promoção de saúde e garantia de direitos de crianças e adolescentes vítimas de violência sexual.

\section{Referências}

Celano, M., Hazzard, A. Campbell, S. K., \& Lang, C. B. (2002). Attribution retraining with sexually abused children: Review of techniques. Child Maltreatment, 7(1), 64-75.

Cohen, J. A, Mannarino, A. P., \& Rogal, S. (2001). Treatment practices for childhood posttraumatic stress disorder. Child Abuse \& Neglect, 25, 123-135.

Cohen, J. A. \& Mannarino, A. P. (2002). Addressing attributions in treating abused children. Child Maltreatment, 7(1), 81-84.

Cohen, J. A., Deblinger, E., Mannarino, A. P., \& Steer, R.A. (2004). A multisite randomized controlled trial for children with sexual abuse-related PTSD symptoms. Journal American Academy of Child and Adolescent Psychiatry, 43(4), 393402. doi: 10.1097/01.chi.0000111364.94169.f9
Cohen, J. A., Mannarino, A. P., \& Knudsen, K. (2005). Treating sexually abused children: One year follow-up of a randomized controlled trial. Child Abuse \& Neglect, 29, 135-145. doi: 10.1016/j. chiabu.2004.12.005

Compton, S. N., March, J. S., Brent, D., Albano, A. M., Weersing, V. R., \& Curry, J. (2004). Cognitive behavioral psychotherapy for anxiety and depressive disorders in children and adolescents: An evidence-based medicine review. Journal American Academy of Childand Adolescent Psychiatry, 43(8), 930-959.

Cortés, D. C., Cantón, J., Justicia, F., \& Cortés M. R. (2011). Un modelo de los efectos del abuso sexual infantil sobre el estrés post-traumático: El rol mediador de las atribuciones de culpa y afrontamiento de evitación. Psicothema, 23(1), 66-73.

Deblinger, E., Stauffer, L. B., \& Steer, R. A. (2001). Comparative efficacies ofsupportive and cognitive behavioral group therapies for young children who have beensexually abused and their nonoffending mothers. Child Maltreatment, 6(4), 332-343.

Del Ben, C. M., Vilela, J. A., Crippa, J. A., Hallak, J. E., Labate, C. M., \& Zuardi, A. W. (2001). Confiabilidade da entrevista estruturada para o DSM-IV - versão clínica traduzida para o português. Revista Brasileira de Psiquiatria, 23(3), 156-159.

Friedman, M. (2009). Transtorno de estresse agudo e pós-traumático. São Paulo: Artmed.

Habigzang, L. F. (2006). Avaliação e intervenção clínica para meninas vítimas de abuso sexual intrafamiliar. Dissertação de Mestrado não-publicada. Curso de Pós-Graduação em Psicologia do Desenvolvimento da Universidade Federal do Rio Grande do Sul. Porto Alegre: UFRGS.

Habigzang, L. F., Stroeher, F., Hatzenberguer, R., Cunha, R. C., Ramos, M., \& Koller, S. H. (2009). Grupoterapia cognitivo-comportamental para crianças e adolescentes vítimas de abuso 
sexual. Revista de Saúde Pública, 43, 70-78. doi: 10.1590/S0034-89102009000800011

Habigzang, L. F. \& Koller, S. H. (2011). Intervenção psicológica para crianças e adolescentes vítimas de violência sexual: Manual de capacitação profissional. Porto Alegre: Casa do Psicólogo.

Habigzang, L. F., Damásio, B. F., \& Koller, S. H. (2013). Impact evaluation of a cognitive behavioral group therapy model in Brazilian sexually abused girls. Journal of Child Sexual Abuse, 22(2), 173-190.

Kristensen, C. H. (1996). Abuso sexual em meninos (Dissertação de mestrado). Recuperado de http://www.lume.ufrgs.br/bitstream/handle/10183/1432/000177073.pdf?sequence $=1$

Kovacs, M. (1992). Children's Depression Inventory Manual. Los Angeles: Western Psychological Services.

Lipp, M. E. \& Lucarelli, M. D. M. (1998). Escala de stress infantil - ESI: Manual. São Paulo: Casa do Psicólogo.

Lucânia, E. L., Valério, N. I., Barison, S. Z. P., \& Miyazaki, M. C. O. S. (2009). Intervenção cognitivo-comportamental em violência sexual: Estudo de caso. Psicologia em Estudo, 14(4), 817-826. doi: 10.1590/S1413-73722009000400022

Maniglio, R. (2009). The impact of child sexual abuse on health: A systematic review of reviews. $\mathrm{Cli}$ nical Psychology Review, 29, 647-657.

Macdonald, G., Higgns, J., Ramchandani, P., Valentine, J. C., Bronger, L. P., Klein, P., O’Daniel, R., Pickering, M., Rademaker, B., Richardson, G., \& Taylor, M. (2012). Cognitive-behaviou- ral interventions for children who have been sexually abused. Campbell Systematic Reviews, 5(3), 1-60. doi: 10.1002/14651858.CD001930 Ministério da Saúde (2002). Notificação de maus-tratos contra crianças e adolescentes pelos profissionais de saúde: Um passo a mais na cidadania em saúde. Brasília: Secretaria de Assistência à Saúde. Recuperado de http://bvsms.saude. gov.br/bvs/publicacoes/notificacao_maustratos_criancas_adolescentes.pdf

Organização Mundial da Saúde (1999). Child Abuse. Recuperado de http://www.who.int/topics/ child_abuse/en/

The Metropolitan Toronto Special Committee on Child Abuse (1995). Child Sexual Abuse Proto$\operatorname{col}\left(3^{\mathrm{a}}\right.$ ed.). Toronto: The Metropolitan Toronto Special Committee on Child Abuse.

Passarela, C. M., Mendes, D. D., \& Mari, J. J. (2010). Revisão sistemática para estudar a eficácia de terapia cognitivo-comportamental para crianças e adolescentes abusadas sexualmente com transtorno de estresse pós-traumático. Revista de Psiquiatria Clínica, 37(2), 60-65.

Whitaker, D. J., Le, Br., Hanson, R. K., Baker, C. K., Mcmahon, P. M., Ryan, G., Klein, A., \& Rice, D. D. (2008). Risk factors for the perpetration of child sexual abuse: A review and meta-analysis. Child Abuse \& Neglect, 32, 529-548.

World Health Organization (WHO) \& International Society for Prevention of Child Abuse and Neglect (ISPCAN). (2006). Preventing child maltreatment: A guide to taking action and generating evidence. Suíça: World Health Organization.
Recebido: agosto 13, 2014

fprovado: agosto 25, 2014 